\title{
PROCESSO DE INTERNACIONALIZAÇÃO DO ENSINO SUPERIOR E MOBILIDADE ACADÊMICA: IMPLICAÇÕES PARA A GESTÃO UNIVERSITÁRIA NO BRASIL
}

\begin{tabular}{c}
\hline INTERNATIONALIZATION PROCESS OF HIGHER \\
EDUCATION IN BRAZIL AND ACADEMIC MOBILITY: \\
IMPLICATIONS FOR UNIVERSITY MANAGEMENT IN BRAZIL \\
PROCESO DE INTERNACIONALIZACIÓN DE LA \\
EDUCACIÓN SUPERIOR Y MOVILIDAD ACADÉMICA: \\
IMPLICACIONES PARA LA GESTIÓN UNIVERSITARIA EN BRASIL
\end{tabular}

Luiza Amália Franklin ${ }^{\mathrm{i}}$

Débora Carneiro Zuin Magnus Emmendoerfer

\begin{abstract}
RESUMO: As universidades convivem com o contexto internacional desde sua gênese, quando recebiam o nome de "Comunidades Internacionais", pois buscavam a universalidade do conhecimento e do saber. Atualmente, a abertura institucional assumiu um papel estratégico para essas organizações, passando a ser parte dos planos de desenvolvimento. Considerando a relevância que a globalização trouxe para todos os tipos de relações entre países e o investimento que o governo brasileiro tem feito no fomento à abertura internacional da educação superior, observou-se a importância de se estudar esse processo no cenário brasileiro. Este estudo buscou, assim, compreender o processo de internacionalização e suas implicações na gestão universitária no Brasil, com ênfase na mobilidade acadêmica. Para tanto, foi feita uma pesquisa analítica que trouxe um levantamento teórico acerca da internacionalização do ensino superior e da mobilidade acadêmica no contexto da gestão universitária no Brasil, bem como seus conceitos e desmembramentos nos últimos anos, além das tendências para o ensino superior. Foi possível verificar implicações de cunho financeiro, tecnológico, cultural e social desse processo não só na gestão universitária, mas também na sociedade de forma geral. Ao fim, compreende-se que a internacionalização do ensino superior brasileiro é um fenômeno paradoxal que traz benefícios para a formação dos acadêmicos e resultados para o país (além de seguir uma tendência mundial), ao mesmo tempo em que é visto como um agente enfraquecedor da soberania nacional e como uma ferramenta econômica que traz privilégios para poucos, devido à sua atuação passiva focada no envio de acadêmicos dos quais se espera retorno econômico.
\end{abstract}

PALAVRAS-CHAVE: Internacionalização. Ensino superior. Gestão universitária.

ABSTRACT: Universities deal with the international context since their genesis, when they were called "International Communities", due to the aim for universalization of expertise and knowledge. Nowadays, the institutional opening took a strategic role for these organizations, becoming part of the development plans. Considering the importance that globalization has brought to all types of relations among countries and the investment that the Brazilian government has made in fostering international opening of higher education, it was noticed the importance of studying this process in the Brazilian context. This research sought, then, to comprehend the internationalization process, as well as to discuss its implications to the Brazilian university management, emphasizing the academic mobility. Therefore, it was developed an analytical research that brought a theoretical mapping on the internationalization of higher education and academic mobility in the university management context in Brazil, as well as its concepts and effects in the recent years, besides the

\footnotetext{
${ }^{1}$ Submetido em: 01/08/2017 - Aceito em: 06/10/2017 - Publicado em: 26/10/2017.
}

\begin{tabular}{l|l|l|l|l|l} 
(C) Rev. Inter. Educ. Sup. & Campinas, SP & v.4 & n.1 & p.130-151 & jan./abr. 2017
\end{tabular}


forecast to the higher education. It was possible to verify financial, technological, cultural and social implications of this process not only to the university management, but also to society in general. Concluding, it was possible to indicate that the internationalization of the Brazilian higher education is a paradox; it brings out benefits to the development of academics and results to the country (besides following the worldwide trend), at the same time that it is seen as a weakening agent of the national sovereignty and an economic tool that favors only a few people due to its passive way of action, focused on out-mobility as it sends out scholars from whom is expected economic feedback.

KEYWORDS: Internationalization. Higher education. University management.

RESUMEN: Las universidades conviven con el contexto internacional desde su génesis, cuando recibían el nombre de "Comunidades Internacionales", porque buscaban la universalidad del conocimiento y del saber. Actualmente, la apertura institucional asumió un papel estratégico para esas organizaciones, convirtiéndose en parte de los planes de desarrollo. Tomando en cuenta la relevancia que la globalización ha traído para todos los tipos de relaciones entre países y la inversión que el gobierno brasileño ha hecho en el fomento a la abertura internacional de la educación superior, resulta interesante destacar la importancia de investigar ese proceso en el escenario brasileño. Esta investigación ha buscado, por tanto, comprender el proceso de internacionalización, y también discutir las implicaciones de este fenómeno en la gestión universitaria brasileña, con el énfasis en la movilidad académica. Para estos fines, se ha hecho una investigación analítica que ha traído un estudio teórico acerca de la internacionalización de la educación superior y de la movilidad académica en el contexto gestión universitaria en Brasil, así como sus conceptos y lineamientos en los últimos años, además de las tendencias para la educación superior. Fue posible verificar implicaciones financieras, tecnológicas, culturales y sociales de ese proceso, pero no solamente en la gestión universitaria, sino también en la sociedad en general. Por fin, se comprende que la internacionalización de la educación superior es una paradoja que trae beneficios para la formación de los académicos y resultados para el país (además de seguir una tendencia mundial), mientras es considerado como un agente debilitador de la soberanía nacional y como una herramienta económica que trae ventajas para pocos, debido a su actuación pasiva, que está concentrada en el envío de académicos de quienes se espera retorno económico.

PALABRAS CLAVE: Internacionalización. Educación superior. Gestión universitaria.

\section{INTRODUÇÃ̃}

Desde a Idade Média, a troca de conhecimento entre culturas diferentes era vista como algo engrandecedor e fundamental nas universitas. Charle e Verger (1996) relatam que estudantes transitavam da Europa Central para a Itália e a França a fim de desenvolver estudos em várias universidades sucessivamente. Essas instituições recebiam o nome de "Comunidades Internacionais", pois buscavam a universalidade do conhecimento e do saber. Além disso, ter a presença de estrangeiros interessados em aprender e compartilhar ensinamentos era sinônimo de prestígio, não só pelo cunho acadêmico da questão, mas também por significar que a instituição é um lugar tolerante, onde prevalecem a paz e a harmonia.

Vários séculos se passaram e esses princípios se mantém, mas com as mudanças que ocorreram na sociedade, também mudaram as relações acadêmicas. Já na era contemporânea, a globalização moldou uma sociedade em que tudo se tornou mais acessível, prático, rápido e padronizado. Como exemplo pode-se apontar o fluxo de informações e o trânsito de pessoas e mercadorias, pontos que facilitaram o compartilhamento de conhecimento entre pesquisadores e instigou ainda mais o interesse da comunidade acadêmica em aprender sob 
diferentes pontos de vista, inseridos em outras culturas. Neste estudo, entende-se "globalização" - tomando por base a perspectiva de Borges e Aquino (2013) - como um fenômeno preponderantemente econômico que influenciou internacionalmente nas relações de consumo e de mercados, devido à sua base capitalista, interferindo inclusive nas dinâmicas institucionais locais. Partindo dessa percepção, é possível vislumbrar impactos de cunho econômico que a mobilidade trouxe para as universidades, e também as diferenças na forma de trabalhar o conhecimento ao redor do mundo.

Essa tendência foi confirmada e, nos últimos anos, o ensino superior tem sido discutido a nível internacional em diversos congressos e encontros que debatem a gestão universitária. Dias (2003, p. 47) explica que nesses eventos os representantes de diversas instituições e de seus respectivos governos se reúnem para "estudar os desafios da educação superior", além de "analisar quais devem ser suas novas missões e verificar como a educação superior tem que atuar para colaborar na construção de uma sociedade melhor”. Essa preocupação surgiu após as Grandes Guerras e está intensificando o processo de homogeneização do modelo universitário em todo o mundo.

Atualmente, ao contrário do que se acredita, o processo de internacionalização do ensino superior não se refere somente à organização de atividades internacionais, tampouco o simples fato de se ter programas de intercâmbio caracteriza uma universidade como uma instituição internacional. Para Harrari (1989), é necessário ter uma política de internacionalização institucional como parte integrante do desenvolvimento estratégico da instituição. Complementando esse raciocínio, Gacel-Ávila (2003) afirma que cabe às autoridades educativas exercer a condução e a liderança do processo de mudança ou adaptação institucional, e não se pode esquecer que tal liderança não deve ser exclusivamente do Reitor, mas de toda uma equipe de colaboradores que deverão estar informados, convencidos e articulados para essa ação. Entende-se, pois, que a política que conduz essas ações deve ser entendida por toda a instituição e fazer parte da cultura organizacional da universidade.

Diversos trabalhos têm sido publicados discutindo esse tema a partir de diversas perspectivas. Borges e Aquino (2013) trataram dos efeitos da globalização e - consequentemente - do capital externo na educação superior brasileira. Abba (2015), por sua vez, fez uma análise comparativa dos departamentos de relações internacionais de universidades argentinas, observando questões como planejamento estratégico, gestão de programas e projetos, entre outros. Afunilando a abordagem dos trabalhos, tem-se o trabalho de Laus (2011), que discorreu sobre o processo histórico de internacionalização da Universidade Federal de Santa Catarina (UFSC).

Considerando a relevância que a globalização trouxe para todos os tipos de relações entre países e as consequências que tais relações trazem consigo, observou-se a importância de se 
estudar a internacionalização das Instituições de Ensino Superior (IES) do Brasil. Além disso, esta pesquisa justifica-se por abordar este tema que tem sido objeto de discussões desde a década de 60, mas que começou a ser priorizado pelo Estado no Brasil nos últimos anos principalmente o fator mobilidade acadêmica - com o programa Ciência sem Fronteiras ( $\mathrm{CsF}$ ) - por isso, os assuntos investigados carecem de teoria direcionada a este contexto. Diante disso, o objetivo principal deste estudo foi compreender o processo de internacionalização e suas implicações deste fenômeno na gestão universitária no Brasil, com ênfase na mobilidade acadêmica.

Como caminho metodológico dessa discussão, optou-se por adotar uma pesquisa de abordagem qualitativa, com o intuito de investigar esse processo por meio da compilação de informações referentes a ele e produzir um material que pode ser fonte para futuros estudos, em que o mesmo processo poderá ser estudado mais a fundo. Tem-se, assim, uma pesquisa analítica, pois - para compreender o processo de internacionalização e suas implicações foram feitas uma narrativa descritiva e uma discussão com as análises sobre as implicações da internacionalização o para a gestão universitária (SEVERINO, 2007; FLICK, 2009).

Realizou-se, segundo os postulados do método bibliográfico, um levantamento teórico acerca da internacionalização do ensino superior e gestão universitária no contexto brasileiro perpassando pela mobilidade acadêmica, bem como seus conceitos e desmembramentos nos últimos anos, além das tendências para o ensino superior no mundo.

\section{INTERNACIONALIZAÇÃO DO ENSINO SUPERIOR}

Para Rudzki (1998), internacionalização das universidades é um processo de mudanças que envolve a análise curricular, a capacitação do corpo acadêmico e da equipe administrativa e o desenvolvimento da mobilidade acadêmica como uma forma de conseguir excelência na docência, na pesquisa e em outras atividades acadêmicas. Laus (2012, p. 28) amplia mais esse conceito e afirma que

[...] a internacionalização de uma universidade corresponde ao processo de diálogo (trabalhos conjuntos, cooperação, intercâmbio, adequação das estruturas institucionais, conflitos e problemas surgidos) com outras universidades ou organizações variadas (empresas, governos, agências internacionais, ONGs) do mundo exterior à fronteira nacional na concepção, desenvolvimento ou implementação de suas funções de ensino, pesquisa e extensão. (LAUS, 2012, p. 28)

Analisando desde o início do uso desse termo, o objetivo explícito da internacionalização durante a Idade Média é bem semelhante ao atual: adquirir conhecimento. O berço das universidades, a Europa, foi onde a interação entre elas começou e se estabeleceu. Com a proximidade geográfica como um fator importante, as universitas enviavam e recebiam professores e estudantes que buscavam novos conhecimentos, experiências diferentes e prestígio diante da comunidade (CHARLE; VERGER, 2002).

\begin{tabular}{l|l|l|l|l|l}
\hline () Rev. Inter. Educ. Sup. & Campinas, SP & v.4 & n.1 & p.130-151 & jan./abr. 2017
\end{tabular}


Vale ressaltar que - no contexto apresentado - apenas os grupos de elite tinham acesso a esse sistema educacional. Para Laus (2012), isso mudou com a Revolução Industrial, quando o conhecimento passou a ser importante no processo produtivo, e a educação começou a ser mais incentivada para que os trabalhadores pudessem, dotados desse conhecimento, produzir mais. Desde então, ser detentor e produtor de conhecimento passou a ser algo almejado pelas economias mais fortes e pelas elites. Iniciou-se, então, uma universalização - mesmo que dentro do país - do saber, uma vez que as nações mais fortes eram aquelas que detinham o conhecimento e o distribuíam entre suas populações da forma mais produtiva possível.

Considerando o contexto de fome, guerras civis e problemas climáticos que se desenvolveu posteriormente, a internacionalização do ensino possui um papel ainda mais significante na sociedade global. Mais especificamente, Severino (2007, p. 22) lista os três objetivos do ensino superior nos dias atuais como sendo: (1) "formação de profissionais das diferentes áreas aplicadas, mediante o ensino/aprendizagem de habilidades e competências técnicas"; (2) formação de pesquisadores, disponibilizando conteúdo e orientando quanto aos métodos adequados e (3) formação do cidadão, guiando-o para o conhecimento do seu papel na sociedade em termos históricos, pessoais e sociais. Sobre este objetivo, ele destaca que se deve "levar o aluno a entender sua inserção não só em sua sociedade concreta, mas também no seio da própria humanidade". Como finalidade maior da universidade, o mesmo autor afirma que é "contribuir para o aprimoramento da vida humana em sociedade".

O que foi dito por Severino (2007) pode ser visualizado após as Grandes Guerras, quando o ensino superior se viu responsável pela reestruturação local - em todo o mundo - da sociedade, e foi dessa preocupação que surgiu o "compromisso básico" dessas instituições: "servir à sociedade" (DIAS, 2003, p. 45), sendo que a cada nação cabe a responsabilidade de definir "que modelo de sociedade se pretende construir".

Com o intuito de se coordenar o papel internacional dessas instituições, vários eventos vêm sendo organizados para promover o debate e o diálogo, e então chegar a ações conjuntas. Em 2009, a UNESCO promoveu a Conferência Mundial sobre Ensino Superior com o tema: "Dinâmicas do Ensino Superior e Pesquisas para a Mudança e o Desenvolvimento Social". Ao final do evento, foi divulgado um documento com algumas reflexões separadas em categorias, e uma delas é "Internacionalização, regionalização e globalização", com onze mensagens. A segunda mensagem traz uma reflexão completa do que deveria ser o processo de cooperação internacional:

[...] instituições de educação superior ao redor do mundo têm uma responsabilidade social de ajudar no desenvolvimento, por meio da crescente transferência de conhecimentos cruzando fronteiras, especialmente nos países subdesenvolvidos, e trabalhando para encontrar soluções comuns para promover a circulação do saber e aliviar o impacto negativo da fuga de cérebros. (UNESCO, 2009, p. 4) 
Esses esforços de garantir os valores do ensino superior não foram suficientes para impedir a influência da globalização. Adotou-se neste trabalho o entendimento de globalização como se vive nos dias de hoje, tomando como marco temporal a Guerra Fria e a vitória do capitalismo, que se disseminou ainda mais e vêm influenciando o globo desde então (BORGES; AQUINO, 2013; LAUS, 2012).

A partir dessa compreensão, foram observadas evidências do crescimento do mercado educacional e da desvirtuação do sistema ao mesmo tempo em que se buscava compreender e aplicar a função social do ensino. Em 1997, o jornal The Economist constatou que "agora, a educação superior se tornou um negócio de massa. Nos dezessete países da OCDE, a proporção daqueles entre 18 e 21 anos na educação superior subiu de 14,4\% em 1985 para 24\% em 1995". Além disso, dados da OCDE (2008) apontam que 40 bilhões de dólares foram gerados em torno apenas da mobilidade estudantil; e o número de alunos estrangeiros cursando ensino superior em países centrais passou de 100,8 milhões no ano de 2000 para 152,5 milhões em 2007 (UNESCO, 2009).

Essas informações desenham um cenário marcado por um "mercado internacional para os serviços de educação superior e pesquisa acadêmica, facilitados pela massificação dos transportes e comunicação pela crescente migração de pessoas e pelo aumento do financiamento e oferta privada de educação superior" (LAUS, 2012, p. 57). Diante disso, entende-se que a mobilidade estudantil passou a ser vista como um investimento econômico, ou seja, que esse cenário de globalização e capitalismo - juntamente com outros fatores. Confirmando esta ideia, Bernheim e Chauí (2008, p. 7) afirmaram que

[...] atualmente, as economias mais avanças se fundamentam na maior disponibilidade de conhecimento. A vantagem comparativa é determinada cada vez mais pelo uso competitivo do conhecimento e das inovações tecnológicas. Esta centralidade faz do conhecimento um pilar da riqueza e do poder das nações, mas, ao mesmo tempo, encoraja a tendência a tratá-lo meramente como mercadoria sujeita às leis do mercado e aberta à apropriação privada. (BERNHEIM; CHAUÍ, 2008, p. 7)

Diante do que foi exposto, entende-se a necessidade de se observar como se deu a internacionalização na gestão universitária brasileira e como ela se configura nos dias atuais. Esses assuntos foram discutidos no tópico a seguir. 


\section{TRAJETÓRIA DA INTERNACIONALIZAÇÃO DO ENSINO SUPERIOR BRASILEIRO}

A internacionalização foi um aspecto basilar do ensino superior brasileiro, uma vez que escolas de nível superior foram criadas com a vinda da família real portuguesa, em 1808, para garantir diploma e prestígio para os nobres, que se formaram profissionais liberais prontos para explorar um amplo mercado. Antes disso, as pessoas que viviam no Brasil e eram afortunadas economicamente enviavam familiares para estudar em universidades europeias porque aqui não existiam tais instituições. Vale destacar que a criação tardia dessas instituições foi própria do nosso país colonizador, pois esse processo se deu diferentemente nas colônias espanholas também situadas nas Américas (como o México, cuja primeira universidade foi criada em 1551). As três primeiras universidades foram criadas na primeira década do século XX e logo foram fechadas, sendo que as pioneiras remanescentes foram criadas já pelos presidentes da época, nos anos 20 - Universidade Federal do Rio de Janeiro e Universidade Federal de Minas Gerais, há menos de cem anos, mostrando o quão jovens sãos as universidades brasileiras (MARTINS, 2002; MENDONÇA, 2005; SANTOS; CERQUEIRA, 2009).

Passando para a compreensão do desenvolvimento do sistema educacional, Laus (2012, p. 37) relata a maior influência externa foi a norte-americana, iniciado pelo investimento do país na expansão do capitalismo - desde o Projeto Truman até o Plano Marshall -, período que perdurou dos anos 1940 até os 1970. Esse cenário culminou com o sistema político de ditadura militar no Brasil (apoiado pelos EUA), marcado pela abertura econômica e pela exposição do país para o mundo, fazendo com que tudo fosse influenciado pelos países mais fortes da época: economia, política, educação, saúde, segurança, etc.

Nesse contexto, foram promulgados os seguintes documentos legais que regulamentavam o ensino superior: Decreto-Lei n. 53, de novembro de 1966, e Decreto-Lei n. 252, de fevereiro de 1967. Por meio desses dispositivos, a educação superior poderia ser vista como um produto passível de ser comercializado sob a forma de "serviços educativos", e isso levou ao início das discussões relacionadas a uma abertura educacional, com um cunho muito mais econômico que educativo. Esses documentos deram início a uma série de ações que culminaram em um acontecimento histórico que sedimentou a base da internacionalização do ensino superior brasileiro: a Reforma Universitária de 1968. Laus explica que ela veio como resposta à necessidade de profissionalização da população, às ambições do governo e às tendências internacionais:

Nesse sentido, a consequente ênfase na profissionalização presente na legislação que norteou a educação nacional a partir dessa época refletiria a necessidade de preparação de quadros considerados aptos para atuarem junto ao crescente empresariado que vinha assumindo o controle econômico do país e dando suporte ao governo militar instalado em 1964. Nesse contexto, foi então sugerida ao país, pelos

\begin{tabular}{l|c|c|c|c|c|}
\hline (C) Rev. Inter. Educ. Sup. & Campinas, SP & v.4 & n.1 & p.130-151 & jan./abr. 2017 \\
\hline
\end{tabular}


documentos elaborados pelos especialistas contratados, uma reforma universitária. É nesse contexto que se insere uma discussão sobre que modelo de desenvolvimento se estava implementando com tais políticas e sobre toda uma evolução que iria ocorrer na negociação dos acordos de cooperação acadêmica e técnico-científica estabelecida pelo país. (LAUS, 2012, p. 39)

Promovida pelo MEC e apresentando, claramente, inspiração no modelo universitário norteamericano, a proposta baseava-se "em princípios de economia e produtividade bem próprios da mentalidade empresarial” (ROMANELLI, 1998, p. 127), propondo a redução de custos, a otimização de recursos humanos e materiais, bem como de espaços físicos.

Vinte anos depois, com o fim da ditadura, houve outro marco histórico: a promulgação da Constituição Federal de 1988 (CF/88). A nova Carta Magna veio com a missão de garantir e universalizar progressivamente os direitos fundamentais. Os princípios que norteiam a educação no Brasil estão discorridos na Seção I do Capítulo III, que vai do artigo 205 ao 2014. De forma geral, este trecho da Carta: estabelece a educação como um direito; disciplina os princípios do ensino; lista os deveres do Estado e as competências de cada instância; traz as condições para o oferecimento do ensino pela iniciativa privada; menciona a questão dos conteúdos mínimos; explicita a aplicação de recursos proveniente de tributos; explana sobre a destinação de recursos a outras instituições de ensino; e menciona a existência de um plano nacional de educação e os objetivos que o norteiam.

Com a $\mathrm{CF} / 88$, o processo de internacionalização passa a ser visto como uma estratégia com ênfase sócio inclusiva pelas IES, em que, no mundo, as ações da Unesco buscavam minimizar o viés economicista, afirmando que a educação deveria ser trabalhada como uma estratégia de desenvolvimento social, por meio do suporte do Estado (UNESCO, 1998). Apesar dessa nova ênfase induzida pela $\mathrm{CF} / 88$ e pelas tentativas das agências internacionais focadas no social, outros órgãos internacionais insistiram na perspectiva econômica, influenciando o sistema brasileiro.

Um fato importante que ilustra esse momento foi a perspectiva da "mobilidade dos alunos e dos professores como consumidores e fornecedores" (LAUS, 2012, p. 50-51). Esse fenômeno foi facilitado pelo "Acordo Geral sobre o Comércio de Serviços" (GATS), assinado por diversos países e proposto pela Organização Mundial do Comércio (OMC), em 1995. O Acordo almejou a liberar aos poucos a prestação de serviços em geral (como educação e saúde), a fim de fomentar a exploração e a participação estrangeiras desses serviços. Em 1999, esse acordo passou a afetar diretamente a educação superior e a mobilidade estudantil:

Pelo Acordo, a educação superior, vista como um produto passível de ser comercializada sob a forma de serviços educativos [...]. [...] o Acordo previa a mobilidade e oferta no exterior de programas e de estabelecimentos de ensino, em quatro modalidades. Essas seriam: fornecimento de educação superior transfronteiriça (onde o fornecedor e o consumidor permanecem cada um em seus países e somente o serviço é oferecido no exterior, como por exemplo, os serviços online e 
a Educação a Distância); o fornecimento para consumo no exterior (onde o consumidor recebe o serviço no país do provedor, por exemplo, mobilidade internacional de estudantes); presença comercial (fornecimento do serviço de educação pela presença comercial no exterior, como por exemplo, os campi satélites, centros de formação empresariais privados) e presença de pessoas físicas (mobilidade internacional de professores). (LAUS, 2012, p. 50-51)

Foi, então, através do GATS que se desenvolveu a internacionalização do ensino no Brasil. Vale destacar que os impactos disso foram além da mobilidade. Nesse mesmo período, foi externalizada, por parte da Capes "a necessidade do estabelecimento de padrões internacionais para a avaliação das atividades de pós-graduação e das pesquisas dela decorrentes desenvolvidas pelas Instituições Públicas" (LAUS, 2012, p. 84); assim começou o fomento das atividades internacionais de docentes e pesquisadores (sem beneficiar os discentes nesse primeiro momento). Com o tempo, programas pequenos e específicos das instituições foram sendo desenvolvidos pelas IES sem um significativo apoio direto do governo. Isso gerou uma autonomia nas instituições e as mesmas se viram responsáveis pelo desenvolvimento de uma gestão universitária sólida e preparada para essa nova realidade. Esse ponto foi mais explorado no tópico seguinte.

\section{MOBILIDADE ACADÊMICA NA GESTÃO UNIVERSITÁRIA NO BRASIL}

Diante da trajetória histórica apresentada, as universidades brasileiras, principalmente as públicas, precisaram adequar sua gestão para acompanharem sua posição estratégica no mercado. Para Trigueiro (1999 apud SAMPAIO; LANIADO, 2009), a própria universidade comporta seus maiores desafios administrativos: "as práticas obsoletas, a dificuldade em se adequar a um novo contexto de relações sociais em um mundo economicamente complexo, caracterizando um conservadorismo persistente".

Han e Zhong (2015, p. 939, tradução nossa) complementam essa discussão e relatam que “com a rápida internacionalização e o desenvolvimento recente da economia do conhecimento, universidades estão agora enfrentando uma concorrência acirrada ao redor do globo e uma maior accountability à sociedade". Este segundo fenômeno se mostra ainda mais evidente nas instituições públicas brasileiras, pois são mantidas por recursos públicos e seus serviços são disponibilizados gratuitamente para a sociedade, o que requer ainda mais responsividade por parte dos agentes da gestão universitária. Para as instituiçõos privadas, o primeiro fenômeno é mais significativo e requer estratégias para o posicionamento das mesmas.

Miura (2006) sintetiza dois tipos de ações de internacionalização que são comuns às instituições públicas e privadas: (1) as parcerias internacionais, que são "acordos institucionais, programas de cooperação, pesquisa conjunta, desenvolvimento tecnológico e mobilidade de estudantes/professores" (p. 72); e (2) as ações relacionadas ao ensino, quais

\begin{tabular}{l|l|l|l|l|c}
\hline (C) Rev. Inter. Educ. Sup. & Campinas, SP & v.4 & n.1 & p.130-151 & jan./abr. 2017
\end{tabular}


sejam estruturar o currículo dos cursos com conteúdo internacional (inclusive com a oferta de disciplinas em língua estrangeira), fomentar a aprendizagem de outros idiomas, promover treinamento intercultural.

É possível compreender, a partir da explanação de Miura, que as ações de internacionalização do conhecimento vão além da mobilidade. Dentre as ações que se pode mencionar, tem-se: publicação de trabalhos em periódicos estrangeiros ou em língua estrangeira ou inglesa; cotutela para dupla titulação e/ou complementação da formação de origem (estágios de ensino/pesquisa e programas particionados sandwich); oferta de atividades de ensino, pesquisa e extensão em língua estrangeira; participar de eventos técnico-científicos no exterior; organizar edições de eventos internacionais no Brasil; programa de capacitação de funcionários nas universidades para atendimento ao público estrangeiro; criar e manter um órgão de relações internacionais; divulgar informações institucionais na internet em língua estrangeira; entre outros. O presente trabalho, por sua vez, optou por discutir a mobilidade acadêmica especificamente, para que fosse possível trazer uma reflexão mais profunda desse tópico.

Diante desse cenário complexo e desafiador, entendeu-se que seria fundamental criar organizações que promovessem a integração e a capacitação dos gestores da área. Para tanto, foi criada - em 1988 - a Associação Brasileira de Educação Internacional (FAUBAI). Essa instituição reúne mais de 180 gestores e responsáveis por assuntos internacionais na educação superior, almejando o "aperfeiçoamento do intercâmbio e da cooperação internacionais como instrumentos para a melhoria do ensino, da pesquisa, da extensão e da administração das instituições filiadas", além de "divulgar a diversidade e as potencialidades das IES brasileiras junto às agências de fomento, representações diplomáticas, organismos e programas internacionais" (FAUBAI, s.d).

Com a coordenação da FAUBAI, foram desenvolvidos debates e estudos que trazem termos próprios do assunto utilizados, os quais são importantes para orientar discussões e guiar avaliações do processo de abertura das universidades. Primeiramente, é importante compreender a diferença entre "mobilidade out" - acadêmicos da IES brasileira em universidades estrangeiras - e "mobilidade in" - acadêmicos de universidades estrangeiras na IES brasileira.

Com relação aos responsáveis pelos processos de mobilidade acadêmica, a FAUBAI (s.d.) os divide em dois grupos: atores internos e externos. Os internos são os que atuam na instituição e são responsáveis por suas políticas e ações. Os agentes que promovem as ações e proporcionam as experiências internacionais fazem parte da equipe administrativa, ou seja, são os gestores que atuam na área. Já os que participam de tais experiências - como professores, alunos e pesquisadores - constituem a equipe acadêmica. 
Entre os atores externos estão as seguintes agências de fomento brasileiras e internacionais: Coordenação de Aperfeiçoamento de Pessoal de Nível Superior (Capes), Conselho Nacional de Desenvolvimento Científico e Tecnológico (CNPq), Edufrance, British Council e Comissão Fulbright. Também se configuram como atores externos as organizações internacionais ligadas ao tema - Organização das Nações Unidas (ONU) Organização dos Estados Americanos (OEA), Banco Interamericano de Desenvolvimento (BID), Organização para a Cooperação e Desenvolvimento Econômico (OCDE) -, os representantes dos governos nacionais e estrangeiros - Ministério da Educação (MEC), Ministério das Relações Exteriores (MRE), Ministério da Ciência e Tecnologia (MCT) - e as instituições de educação superior, assim como os organismos de investigação e desenvolvimento.

Quanto à categorização dos tipos de internacionalização, por fim, tem-se a ativa e a passiva. Lima e Maranhão (2009) explicam que aquele tipo foca no acolhimento e na atração de pessoas - mais comum em países desenvolvidos, enquanto este direciona suas políticas para a emissão de acadêmicos, devido à falta de preparação institucional e estatal para tal atração. Esses modelos trazem consequências distintas para a instituição e requerem políticas específicas para que não se perca o potencial dos resultados. $\mathrm{O}$ caso brasileiro se encaixa, de forma geral, na atuação passiva, devida à ausência de infraestrutura e de políticas que atraiam pesquisadores estrangeiros, uma vez que as ações são focadas na mobilidade out de forma puramente reativa.

De posse dos termos que compõem essa discussão, outros aspectos norteadores precisam ser trabalhados neste tópico. Começando pelos compromissos da gestão universitária das IES brasileiras, Ribeiro (2014) analisou 27 estatutos e constatou que as universidades propõem as seguintes ações:

incentivar, promover e estimular o intercâmbio com outras instituições e organizações científicas e técnicas, nacionais e estrangerias, visando o desenvolvimento das ciências e das artes, preservando a natureza e interagindo com o ecossistema; colaborar com entidades públicas e privadas através de estudos, projetos, pesquisas e serviços, com vistas à solução de problemas regionais e nacionais sem perder de vista os valores éticos, ecológicos, em consonância com os anseios e tradições dos povos da região; prestar serviços à comunidade por meio de programas e projetos sociais e da realização de cursos, eventos e campanhas públicas que evolvam, sempre que possível, parcerias com outras instituições e/ou movimentos sociais organizados; promover a integração cultural na perspectiva da pluralidade dos povos e da sua integração internacional; manter a universidade aberta à participação da população, mediante amplo e diversificado intercâmbio com instituições, organizações e movimentos da sociedade; congregar professores, cientistas, técnicos e artistas, assegurando-lhes os necessários meios materiais e as indispensáveis condições de autonomia e de liberdade para se devotarem à ampliação do conhecimento ao cultivo das artes e às suas aplicações a serviço da sociedade. (RIBEIRO, 2014, pp. 9-10)

Juntamente com o aumento da complexidade da gestão universitária, intensificou-se também a formalização do processo de internacionalização das IES. Gacel-Ávila (1999, p. 38) afirma 
que o "processo de internacionalização deve ser visto como uma abertura institucional para o exterior" e, por isso, deve ser parte das diretrizes e dos planos de desenvolvimento institucional, para que esse processo seja desenvolvido de fora estratégica e articulada aos objetivos da organização.

Essa formalização e as oportunidades para os estudantes chegaram com a mesma motivação: econômica. O programa de mobilidade que ilustra esse cenário nos dias atuais é o Ciência sem Fronteiras, instituído pelo Decreto-Lei n. 7.642/2011. Spears (2014, p. 11) explica a principal motivação que levou o governo brasileiro a lançar o CsF:

A emergência no âmbito da economia mundializada como participante do BRIC (Brasil, Rússia, Índia, China e África do Sul) mobilizou o governo federal brasileiro a estabelecer um programa estatal de mobilidade acadêmica (Programa Ciência sem Fronteiras) de modo a fazer avançar o capital social do país (general intellect) e a infraestrutura em STEM (Ciência, Tecnologia, Engenharia e Matemática) relacionadas à indústria (SPEARS, 2014, p. 11)

A destinação de vagas apenas para as áreas supracitadas confirma isso. De acordo com Plano do Programa Ciência sem Fronteiras ${ }^{2}$ divulgado pela Capes, a meta do foi enviar 75.000 bolsistas para o exterior até o final de 2014, sendo que o programa começou oficialmente no segundo semestre de 2011. Até o mês de agosto de 2014, já tinham sido implementadas 70.188 bolsas de graduação e pós-graduação, sendo que 31.825 delas foram destinadas à área de "Engenharias e demais áreas tecnológicas", e 29\% do total de estudantes (20.358) foram para os Estados Unidos, o que é um claro reflexo da Reforma Universitária e da tendência capitalista do cenário atual.

Para melhor observar esses reflexos, consultou-se o International Association of Universities (IAU) que desenvolveu neste ano a IAU 4th Global Survey: Internationalization of Higher Education - Growing expectations, fundamental values - pesquisa que consultou 1.336 instituições em 131 países. "O relatório apresenta a maior e mais geograficamente abrangente coleta de dados primários sobre internacionalização da educação superior disponível hoje". Destacam-se alguns pontos dessa pesquisa:

a) Mais de metade das instituições pesquisadas possuem uma política e/ou estratégia de internacionalização;

b) Mobilidade estudantil e colaboração para pesquisa internacional são as maiores prioridades das instituições;

c) Conhecimentos dos estudantes acerca de assuntos internacionais é o benefício mais significante que se espera da internacionalização. Esse resultado também foi encontrado na terceira (2009) e na segunda (2005) edições da pesquisa;

\footnotetext{
${ }^{2}$ Ciências sem Fronteiras: um programa especial de mobilidade internacional em ciência, tecnologia e inovação. Disponível em: http://www.capes.gov.br/images/stories/download/Ciencia-semFronteiras_DocumentoCompleto_julho2011.pdf. Acesso em: 30 de setembro de 2014.
}

\begin{tabular}{|l|l|l|l|l|l|}
\hline C Rev. Inter. Educ. Sup. & Campinas, SP & v.4 & n.1 & p.130-151 & jan./abr. 2017
\end{tabular}


d) $\mathrm{O}$ fato de oportunidades internacionais serem disponíveis apenas para estudantes que possuam recursos financeiros foi considerado o maior risco potencial da internacionalização para as instituições, enquanto o maior risco social é a mercantilização/comercialização da educação;

e) Na maioria das regiões, o foco geográfico das universidades é sua própria região. A Europa também é um foco para a maior parte dos respondentes;

f) Recursos limitados é o maior obstáculo interno e externo, o que também foi constatado nas duas últimas pesquisas;

g) Os respondentes relatam que buscam promover valores de igualdade e partilha dos benefícios por meio das estratégias e atividades de internacionalização.

Os pontos “a”, "d", "f" e "g" podem ser observados na realidade brasileira. Contudo, o quinto tópico não corresponde ao contexto nacional, uma vez que as instituições brasileiras buscam universidades de excelência para assinar convênios e estes institutos estão localizados em outros continentes, situados principalmente no hemisfério norte. $\mathrm{O}$ mesmo ocorre com o segundo e terceiro pontos, mostrando que o Brasil ainda tem muito para evoluir no quesito internacionalização para acompanhar o cenário das principais universidades do mundo.

Este trabalho se propôs também a discutir as implicações desse processo na gestão universitária e as tendências foram traçadas para o futuro do ensino superior brasileiro. Esses pontos foram trabalhados na próxima seção.

\section{IMPLICAÇõES DA INTERNACIONALIZAÇÃO E TENDÊNCIAS PARA O ENSINO SUPERIOR}

O fenômeno exposto até aqui ilustra a transformação do ensino superior em uma mercadoria a ser vendida ao capital internacional. Quanto a isso, Borges e Aquino (2013, p. 31) explicam que há uma perda do propósito oficial da internacionalização, uma vez que ocorre "uma adaptação às novas formas sociais de produção e reprodução do sistema capitalista, partindo do pressuposto de que quem é hegemônico concebe a política econômica internacional de modo a poder sustentar seus próprios interesses e ideologias". Os autores complementam esse raciocínio afirmando que isso “implica na diminuição de barreiras para o 'livre comércio' do setor, num caminho que pode levar à perda da autonomia universitária e da diversidade cultural". Ilustra-se, assim, um cenário em que a identidade da instituição, os assuntos considerados relevantes localmente e a cultura local ficam ameaçados diante de uma interferência externa.

Outras implicações culturais podem ser observadas ao se refletir acerca da mobilidade in. Não se tem o hábito de praticar - de forma periódica - a comunicação oral e escrita em língua estrangeira nos campi de universidades brasileiras, além de haver uma incapacidade físico-

\begin{tabular}{l|l|l|l|l|l}
\hline (C) Rev. Inter. Educ. Sup. & Campinas, SP & v.4 & n.1 & p.130-151 & jan./abr. 2017 \\
\hline
\end{tabular}


humana dos órgãos de relações internacionais terem uma postura proativa em assessorar para além da alta gestão universitárias, gerando demandas reprimidas nas unidades de ensino/pesquisa, muitas vezes por desconhecimento e falta de informação, que uma assessoria internacional poderia facilitar $\mathrm{e}$ promover de modo integrado. Isso prejudica $\mathrm{o}$ desenvolvimento de uma atuação ativa de internacionalização, que pode lesar a imagem da instituição e afetar futuras parcerias, além de comprometer o aproveitamento potencial dessas experiências.

Esse contexto também contempla questões financeiras ao considerar a escassez de recursos para viabilizar e manter esse processo, questão ainda mais latente em tempos de crise político-econômica. Além disso, verificam-se as limitações tecnológicas para compartilhar conhecimento e negociar parcerias, a fim de realizar essas práticas de internacionalização. Essas limitações levam à vulnerabilidade das instituições públicas e privadas de ensino ao capital internacional, uma vez que elas possuem poucas opções de captação de recursos para driblar esses obstáculos. Essa vulnerabilidade pode enviesar o conhecimento transmitido, limitar e/ou direcionar as áreas de investigação dos pesquisadores, descaracterizar a atuação local da instituição, desprivilegiar campos do conhecimento que não trazem retorno financeiro direto a investidores, entre outras consequências.

Há também implicações de cunho social nesse processo. Entende-se que o contato direto com outras culturas e pontos de vista é enriquecedor pessoal e profissionalmente, não só para aqueles que tiveram a oportunidade de participar de mobilidade, mas também para o ambiente acadêmico de forma geral. Algumas das conquistas desse fenômeno são aquisição de proficiência em uma língua estrangeira, surgimento de novas ideias e perspectivas como resultado do contato com métodos diferentes de ensino e pesquisa, desenvolvimento de habilidades interpessoais, experiências pessoais e acadêmicas adquiridas, aumento da tolerância na convivência entre as pessoas, obtenção de financiamentos devido ao aumento da visibilidade da instituição e conquista do respeito de outras instituições.

Negativamente, é possível observar que os intercâmbios - como são feitos atualmente atenuam as desigualdades existentes no meio acadêmico. Ao selecionar estudantes que já possuem a proficiência na língua e bons resultados em seus históricos escolares, o sistema apenas incrementa os conhecimentos que poucos já possuem. Além disso, verificou-se que a prática do fomento de fechamento de parcerias nas áreas do conhecimento que trazem retorno monetário, excluindo alguns campos de estudo e gerando um obstáculo para o enriquecimento de pesquisas nos mesmos.

Além dessas implicações, discutir previsões é importante para guiar os planejamentos e as discussões acerca do assunto de forma solidamente embasada, com condições reais de se trazer resultados positivos. Em dezembro de 2003, Porto e Régnier lançaram o livro "O Ensino Superior no Mundo e no Brasil - Condicionantes, Tendências e Cenários para o

\begin{tabular}{l|c|c|c|c|c|}
\hline (c) Rev. Inter. Educ. Sup. & Campinas, SP & v.4 & n.1 & p.130-151 & jan./abr. 2017
\end{tabular}


Horizonte 2003-2025: Uma Abordagem Exploratória" como um mapeamento do futuro do ensino superior no Brasil e no mundo, baseado no passado e nas mudanças que vêm ocorrendo com o tempo. Ao analisar o processo de internacionalização, os autores chegaram a quatro cenários ilustrados no diagrama abaixo (Figura 1). Abaixo da figura, há resumos das explicações dadas acerca dos cenários em si e a focalização do contexto no ensino superior (BRASIL, 2003).

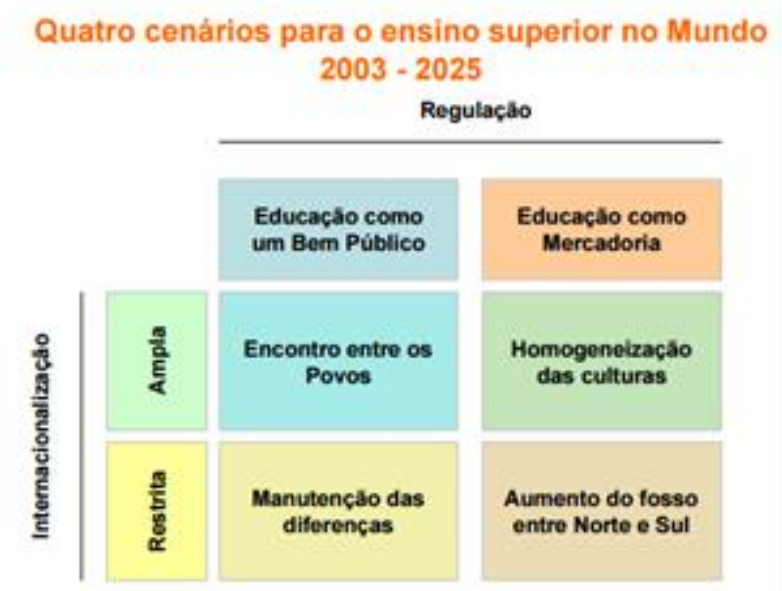

Figura 1. Quatro cenários para o ensino superior no Mundo 2003-2025 Fonte: BRASIL, 2003.

A cooperação é a ideia principal do Cenário 1 - Encontro entre os Povos: Educação como um Bem Público em um Contexto de Ampla Internacionalização. Assim, após várias turbulências e diversos conflitos que marcaram o século passado, organismos internacionais ganham força e as esferas política, econômica e social colaboram para as relações internacionais no meio educacional, tanto que levam ao estímulo dos estudos na área das ciências humanas (incluindo pesquisas puramente culturais sobre pequenos grupos) - mesmo que elas não tragam resultados aplicados diretamente no setor produtivo - e à reformulação do ensino a distância. Vale salientar que os padrões de qualidade devem ser cada vez mais observados para que o processo de validação de diplomas seja feito com mais facilidade. Com relação à internacionalização em si, observa-se a assinatura de "parcerias internacionais para a expansão do sistema de ensino superior nos países em desenvolvimento" (p. 47) e a "criação de um fundo internacional de financiamento da educação superior” (p. 48).

"O mundo é uma grande cadeia de produção onde cada um busca se integrar da melhor forma" (p. 49); assim se resume o Cenário 2 - Homogeneização das culturas: Educação como Mercadoria em um Contexto de Ampla Internacionalização. Internet, concorrência, evolução do sistema financeiro, fluxos de capital e bolsões de pobreza não deixam de influenciar o sistema educacional e fazer com que a educação se torne uma resposta para as necessidades empresariais, tirando o espaço das artes e das ciências humanas. Em suma, "a educação cresce em importância e continua sendo a principal força motriz da inovação e 
competitividade dos países" (p. 50), o que leva a um aumento nos investimentos em educação e nos lucros de grandes corporações educacionais, à elaboração de rankings globais baseados nos padrões de qualidade definidos e à perda do patrimônio cultural de comunidades devido à padronização do ensino.

O Cenário 3 - Manutenção das Diferenças: Educação como um Bem Público em um Contexto de Internacionalização Limitada - se baseia na ideia de que "o mundo é dividido em grandes impérios" (p. 60) devido à estagnação da globalização e da concentração do poder e da capacidade produtiva nos países centrais. Com isso, perde-se a esperança de um sistema econômico mais justo e equilibrado, principalmente depois da volta do protecionismo e do enfraquecimento dos organismos internacionais que atuavam no mercado. Isso tudo leva a consequências diversas, como o agravamento de problemas sociais, estagnação das economias emergentes, falta de cooperação e aumento das diferenças de modo geral. Quanto ao ensino superior, ele se vê ainda mais influenciado pela economia, o que é percebido nas integrações entre blocos regionais (principalmente por meio dos intercâmbios acadêmicos) e negociações de reconhecimento de diploma. Por outro lado, o protecionismo pode ser notado na preservação de heranças culturais, nas restrições nas relações com universidades no exterior e na busca pelo desenvolvimento local. De forma geral, esse cenário ilustra um grande desenvolvimento do ensino superior, contando com a UNESCO, com o os governos e com fundos de fomento, o que gera crescimento da oferta em instituições públicas, auxílio do governo para financiamento dos estudos em faculdades particulares, avaliação da qualidade e da empregabilidade dos cursos, aumento da oferta de cursos à distância e aprimoramento do uso de tecnologias no processo ensino-aprendizagem.

Por fim, o Cenário 4 - Aumento do fosso entre Norte e Sul: Educação como Mercadoria em um Contexto de Internacionalização Limitada - está num contexto de hiperconcorrência mundial, que conta com uma OMC enfraquecida, um "comércio internacional turbulento e instável" (p. 56), uma globalização em retrocesso, pouca cooperação e "reduzido crescimento econômico mundial e crises de liquidez" (p. 57). Respostas a esse cenário se mostram falhas, imediatistas e instáveis, levando a conflitos étnicos, piora nas condições de emprego, "crescimento da violência e contravenção" e, apesar de tudo, "pouca mobilidade social" (p. 57). No quesito educacional, notam-se a falta de limites na busca por dinheiro, a redução dos fluxos de intercâmbio, a queda na qualidade do ensino em países em desenvolvimento, diferenças crescentes entre universidades, esvaziamento da Unesco, concorrência acirrada, crises e falências em várias instituições e pouco auxílio para os grupos sociais em desvantagem.

Ao analisar essas tendências à luz das discussões deste artigo, observa-se que o Brasil se encaixa no segundo cenário - Homogeneização das Culturas - Educação como Mercadoria em um Contexto de Ampla Internacionalização, pois está passando por um fenômeno de ampla internacionalização, motivada por interesses econômicos, cujos resultados para o

\begin{tabular}{l|l|l|l|l|l}
\hline (C) Rev. Inter. Educ. Sup. & Campinas, SP & v.4 & n.1 & p.130-151 & jan./abr. 2017
\end{tabular}


ensino em si são tendenciosos, além de os investimentos excluírem as artes e as ciências humanas.

\section{CONSIDERAÇÕES FINAIS}

Este estudo teve como objetivo descrever o processo de internacionalização na gestão universitária brasileira, por meio de contextualização histórica, levantamento de conceitos relacionados ao assunto e discussão das implicações e tendências deste fenômeno. Essas reflexões foram levantadas com o intuito de servir de material de apoio para as ações dos atores internos e externos envolvidos no processo - desde estudantes, passando por professores, servidores e gestores universitários, até chegar aos responsáveis pelas políticas públicas do tema - para que os pontos que foram levantados sejam considerados ao se pensar a gestão universitária e seu caráter internacional.

Nesta pesquisa, entendeu-se que a internacionalização é um processo que não afeta apenas o sistema de ensino em si. Suas implicações são também sociais, culturais e econômicas, e os custos e os benefícios deste fenômeno se estendem à sociedade. Por isso, compreendeu-se a relevância de se fazer o planejamento desse processo em consonância com os propósitos da gestão da universidade e do governo. Além disso, a interação com outras IES se faz necessária para a troca de experiência e crescimento mútuo, o que faz da criação da FAUBAI um passo importante para a evolução do processo de internacionalização não só no quesito mobilidade acadêmica, mas na adequação da instituição como um todo.

Essas conquistas mencionadas estão presentes na realidade de instituições europeias tradicionais há séculos, localizadas em nações cuja proposta de universalização do ensino se faz presente desde a Idade Média. Por ser um país mais jovem, o cenário comum para países europeus representa um objetivo estratégico para o Brasil, que tem muito a evoluir.

Por outro lado, discutiu-se as questões negativas do processo. Ao se observar a evolução da educação superior no Brasil, por exemplo, nota-se a grande influência norte-americana, principalmente na Reforma de 1968, que iniciou oficialmente o fomento à mobilidade internacional, o que impulsionou o fenômeno de forma geral. Esse fomento levou a uma mobilidade tendenciosa, com tendências econômicas, que ameaçam a difusão do conhecimento, principalmente em áreas cujas pesquisas não geram retorno financeiro direto. Se fossem consideradas as necessidades da sociedade brasileira como um todo - e não a economia do país somente -, deveria ser feita uma avaliação das necessidades das áreas de educação, saúde, transporte, cidadania para se adaptar à gestão governamental e institucional do processo de internacionalização das universidades.

Com tudo isso, compreende-se que a internacionalização do ensino superior brasileiro é um fenômeno paradoxal que traz benefícios para a formação dos estudantes e resultados para o 
país (além de seguir uma tendência mundial), ao mesmo tempo em que não deixa de ser visto como um agente enfraquecedor da soberania nacional e como uma ferramenta econômica que traz benefícios para poucos, devido à sua atuação passiva focada no envio de acadêmicos dos quais se espera retorno à economia.

Para minimizar esses efeitos, sugere-se que o governo e as instituições de ensino pensem estrategicamente seus projetos de abertura internacional para não se distanciarem dos objetivos angulares dessa abertura e não diminuir os benefícios potenciais de longo prazo ao considerar apenas os retornos imediatistas. Refletindo sobre o futuro, foi possível perceber que tendência que melhor se aproxima à realidade brasileira é a ilustrada pelo Cenário 2: "Homogeneização das Culturas - Educação como Mercadoria em um Contexto de Ampla Internacionalização". Um dos fatores que justificam essa inferência é o incentivo maior para os intercâmbios das áreas de exatas e agrárias no ensino superior brasileiro, tendo como maior exemplo disso o CsF. Isso traz a possibilidade de que as instituições estejam cedendo à ameaça da mercantilização/comercialização da educação, considerado o maior risco social da internacionalização pela pesquisa da IAU.

Vale salientar também que a concretização desse cenário pode prejudicar a identificação dos estudantes com a cultura brasileira e ocasionar uma fuga de cérebros crônica, cenário já intensificado pela atuação passiva das instituições, fazendo com que os investimentos feitos em mobilidade não tragam os resultados esperados para o país.

Conclui-se, então, que a internacionalização é uma das prioridades das IES atualmente. Contudo, nem o governo nem as instituições estão dando a devida atenção às ameaças que estão por trás dos benefícios, minimizando os logros de longo prazo ao desenvolver uma internacionalização que margeia a razão de ser da educação, algo que se iniciou no país com a Reforma de 1968 e prevalece até então.

\section{REFERÊNCIAS}

ABBA, Maria Julieta. Las oficinas de relaciones internacionales en el proceso de internacionalización de la educación superior. Un análisis a través de variables de gestión.

Revista Gestão Universitária na América Latina-GUAL, v. 8, n. 4, p. 20-37, 2015.

Disponível em: <https://periodicos.ufsc.br/index.php/gual/article/view/19834535.2015v8n4p20>. Acesso em: 10 jun. 2017.

BERNHEIM, Carlos Tünnerman; CHAUÍ, Marilena de Souza. Desafios da universidade na sociedade do conhecimento. Paris: UNESCO, 2008. Série Documentos Ocasionais do Fórum da UNESCO. Disponível em: < http://unesdoc.unesco.org/images/0013/001344/13442 2por.pdf >. Acesso em 20 jul. 2016. 
BRASIL. Constituição (1988). Capítulo III, artigos 205 a 2014, Brasília, DF. Disponível em: < http://www.planalto.gov.br/ccivil_03/constituicao/constituicao.htm>. Acesso em: 20 jul. 2014.

BRASIL. Decreto-lei no 53, de 18 de novembro de 1966. Presidência da República, Brasília, DF. Disponível em < http://www2.camara.leg.br/legin/fed/declei/1960-1969/decreto-lei-5318-novembro-1966-373396-norma-pe.html>. Acesso em 20 jul. 2014.

BRASIL. Decreto-lei no 252, de 28 de fevereiro de 1967. Presidência da República, Brasília, DF. Disponível em < http://www2.camara.leg.br/legin/fed/declei/1960-1969/decretolei-252-28-fevereiro-1967-376151-norma-pe.html>. Acesso em 20 jul. 2014.

BRASIL. Decreto-lei no 7.642, de 13 de dezembro de 2011. Presidência da República, Brasília, DF. Disponível em < http://www.cienciasemfronteiras.gov.br/documents/214072/

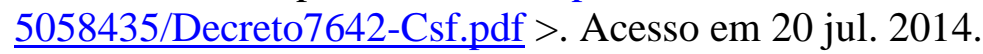

BRASIL. Ministério da Educação. Ensino superior no mundo e no Brasil: Tendências e cenários 2003-2025. 2003. Disponível em:

$<$ http://portal.mec.gov.br/sesu/arquivos/pdf/ensinosuperiormundobrasiltendenciascenarios200 3-2025.pdf>. Acesso em: 30 set. 2016.

BORGES, Vanessa Maria de Oliveira; AQUINO, Edson Tomaz de. Ensino superior à ordem do capital internacional. Revista Gestão Universitária na América Latina-GUAL, v. 6, n. 2, p. 22-32, abr. 2013. Disponível em: < https://periodicos.ufsc.br/index.php/gual/article/ viewFile/1983-4535.2013v6n2p22/24565> Acesso em: 30 set. 2016.

CHARLE, Christophe; VERGER, Jacques. História das universidades. São Paulo: Editora da UNESP, 1996. 131 p. ISBN 8571391092.

DIAS, Marco Antônio Rodrigues. Espaços Solidários em Tempos de Obscurantismo. In: MORHY, Lauro (Org.). Universidade no mundo: universidade em questão. Brasília: UNB, 2003. 608 p. ISBN 8523007997.

FAUBAI. Sobre a FAUBAI. s.d. Disponível em: $<$ http://faubai.org.br/pt-br/sobre-a-faubai $>$. Acesso em: 21 jul. 2016.

FLICK, Uwe. Desenho da pesquisa qualitativa. Porto Alegre: Artmed, 2009. 167 p. ISBN 8536321350 .

GACEL-ÁVILA, Jocelyne. Internacionalizacion de la educación superior en America Latina y el Caribe: reflexiones y lineamientos. Guadalajara: Organisation Universitaire Interamericaine y La Asociation Mexicana para la Educacion Internacional, 1999. 210 p. ISBN 9688958778. 
GACEL-ÁVILA, Jocelyne. La Internacionalizacion de la education superior: paradigma para la ciudadania global. Guadalajara: Universidad de Guadalajara, 2003. 390 p. ISBN 9702703190.

HARRARI, Maurice. Report \#1, internacionalization of higher education: effecting institutional change in the curriculum and campus. Long Beach: Center for International Education, California State University, 1989. 32 p.

HAN, Shuangmiao; ZHONG, Zhou. Strategy maps in university management: A comparative study. Educational Management Administration \& Leadership, v. 43, n. 6, p. 939-953, 2015. Disponível em: <http://journals.sagepub.com/doi/abs/10.1177/1741143214552860\# articleCitationDownloadContainer>. Acesso em: 30 set. 2016.

LAUS, Sonia Pereira. As contingências históricas e o ensaio precoce do que se consolidaria como o processo de internacionalização da UFSC. Revista Gestão Universitária na América Latina-GUAL, v. 4, n. 4, p. 208-226, 2011. Disponível em: <https://periodicos. ufsc.br/index.php/gual/article/view/1983-4535.2011v4nespp208>. Acesso em: 30 set. 2016.

LAUS, Sonia Pereira. A internacionalização da educação superior: um estudo de caso da Universidade Federal de Santa Catarina. 2012. Tese (Doutorado em Administração) - Escola de Administração, Universidade Federal da Bahia, 2012.

LIMA, Manolita Correia; MARANHAO, Carolina Machado Saraiva de Albuquerque. O sistema de educação superior mundial: entre a internacionalização ativa e passiva. Avaliação, Sorocaba, v.14, n.3, p. 583-610, 2009. Disponível em: <www.scielo.br/pdf/aval/v14n3/ a04v14n3.pdf>. Acesso em: 10 set. 2016.

MARTINS, Antonio Carlos Pereira. Ensino Superior no Brasil: da descoberta aos dias atuais. Acta Cirúrgica Brasileira, v.17, n.3, p. 4-6, 2002. Disponível em: <http://www.scielo.br/ scielo.php?script=sci_arttext\&pid=S0102-86502002000900001>. Acesso em: 15 set. 2016.

MENDONÇA, Tânia Regina Broeitti. Brasil: O Ensino Superior às primeiras universidades Colônia - Império - Primeira República. In: SEMINÁRIO NACIONAL ESTADO E POLÍTICAS SOCIAIS NO BRASIL, 2, 2005, Cascavel. Anais do... Cascavel: Universidade Estadual do Oeste do Paraná, 2005.

MIURA, Irene Kazumi. O processo de internacionalização da Universidade de São Paulo: um estudo de três áreas do conhecimento. 2006. Tese (Livre Docência) - Faculdade de Economia, Administração e Contabilidade, Universidade de São Paulo, Ribeirão Preto, 2006.

RIBEIRO, Raimunda Maria da Cunha. Os Desafios Contemporâneos da Gestão Universitária: Discursos Politicamente Construídos. In: CONGRESSO IBERO-AMERICANO DE POLÍTICA E ADMINISTRAÇÃO DA EDUCAÇÃO, 4, 2014. Comunicações orais. Cidade do Porto: Escola Superior de Educação do Instituto Politécnico do Porto, 2014. Disponível em: <http://www.anpae.org.br/IBERO_AMERICANO_IV/GT2/GT2_Comunicacao/ RaimundaMariadaCunhaRibeiro_GT2_integral.pdf>. Acesso em: 12 set. 2016. 
ROMANELLI, Otaíza de Oliveira. História da educação no Brasil (1930/1973). 40. ed. Petrópolis: Vozes, 1998. 279 p. ISBN 9788532602459.

RUDZKI, Romuald Edward John. The strategic management of internationalization: towards a model of theory and practice. 1998. Tese (Doutorado em Filosofia) - Escola de Educação, University of Newcastle upon Tyne, United Kingdom, 1998.

SAMPAIO, Rosely Moraes; LANIADO, Ruthy Nadia. Uma experiência de mudança da gestão universitária: o percurso ambivalente entre proposições e realizações. Revista de Administração Pública - RAP, v.43, n.1, p. 151-174, 2009. ISSN 0034-7612. Disponível em: 〈http://dx.doi.org/10.1590/S0034-76122009000100008>. Acesso em: 21 jul. 2016.

SANTOS, Adilson Pereira dos; CERQUEIRA, Eustáquio Amazonas de. Ensino Superior: trajetória histórica e políticas recentes. In: COLÓQUIO INTERNACIONAL SOBRE GESTÃO UNIVERSITÁRIA NA AMÉRICA LATINA, 9, 2009, Florianópolis. Anais do...

Florianópolis: Instituto de Pesquisas e Estudos em Administração Universitária, 2011. p.1-17.

SANTOS, Gildenir Carolino; PASSOS, Rosemary (Colab.). Percurso científico: guia prático para elaboração da normalização científica e orientação metodológica. Campinas, SP: Arte Escrita, 2012. 157 p., il. (Manuais técnicos BFE, n.7). ISBN 9788564830073. Disponível em: <http://www.bibliotecadigital.unicamp.br/document/?code=49038\&opt=4>. Acesso em: 7 jul. 2014.

SPEARS, Eric. O valor de um intercâmbio: mobilidade estudantil brasileira, bilateralismo \& internacionalização da educação. Revista Eletrônica de Educação, v. 8, n. 1, p. 151-163, 2014. Disponível em: <http://www.reveduc.ufscar.br/index.php/reveduc/article/viewFile/ 1005/311>. Acesso em: 21 jul. 2016.

SEVERINO, Antônio Joaquim. Metodologia do trabalho científico. 23 ed. São Paulo: Cortez, 2007. 303 p. ISBN 9788524913112

STALLIVIERI, Luciane. O processo de internacionalização das instituições de ensino superior avaliação, qualidade e pertinência da cooperação internacional. In: REUNIÃO ANUAL DA FAUBAI, 20., 2008, Bonito. [Anais..Bonito: FAUBAI, 2008.

UNESCO. Conferência Mundial sobre o Ensino Superior, 2009. As novas dinâmicas do ensino superior e pesquisas para a mudança e o desenvolvimento social. Paris: UNESCO, 2009. Disponível em: <http://portal.mec.gov.br/index.php?option=com_docman\&view= download\&alias=4512-conferencia-paris\&category_slug=abril-2010-pdf\&Itemid=30192 > . Acesso em: 21 jul. 2016.

\section{Agradecimentos}

Os autores agradecem à Fundação de Amparo à Pesquisa do Estado de Minas Gerais (FAPEMIG) pelo fomento estudantil. 


\footnotetext{
${ }^{\mathrm{i}}$ Sobre os autores

Luiza Amália Soares Franklin

luizafranklin.ufv@gmail.com / ORCID: http://orcid.org/0000-0001-5385-7161

Universidade Federal de Viçosa (UFV) - Brasil

Graduada em Secretariado Executivo Trilíngue pela FV

Debora Zuin

dzuin@ufv.br / ORCID: http://orcid.org/0000-0002-2077-5861

Universidade Federal de Viçosa (UFV) - Brasil

Doutora ( $\mathrm{PhD}$ ) em Estudos Organizacionais pela University of Edinburgh Business School, UK

\section{Magnus Emmendoerfer}

magnus@ufv.br / ORCID: http://orcid.org/0000-0002-4264-8644

Universidade Federal de Viçosa (UFV) - Brasil

Pós-doutor em Ciências da Administração (Concentração em Administração Pública) na Universidade do Minho e em Turismo na Universidade do Algarve, Portugal.
} 